\title{
Electron-Irradiation and Photo-Excitation Darkening and Bleaching of Yb Doped Silica Fibers: Comparison
}

\author{
Alexander V. Kir'yanov \\ Centro de Investigaciones en Optica, Leon, Mexico \\ E-mail: kiryanov@cio.mx \\ Received September 25, 2011; revised October 28, 2011; accepted November 10, 2011
}

\begin{abstract}
We report a comparative experimental study of the attenuation spectra transformations for a series of $\mathrm{Yb}$ doped alumino-germano silicate fibers with different contents of $\mathrm{Yb}^{3+}$ dopants, which arise as the result of irradiation either by a beam of high-energy electrons or by resonant (into the $977 \mathrm{~nm}$ absorption peak of $\mathrm{Yb}^{3+}$ ions) optical pumping. The experimental data obtained reveal that in the two circumstances, substantial and complex but different in appearance changes occur within the resonant absorption band of $\mathrm{Yb}^{3+}$ ions and in the off-resonance background loss of the fibers. Possible mechanisms responsible for these spectral changes are discussed.
\end{abstract}

Keywords: Ytterbium Doped Silica Fibers, Photodarkening, Electron Irradiation

\section{Introduction}

$\mathrm{Yb}^{3+}$ doped silica fibers (YFs) with different core glass hosts co-doped with aluminum, germanium, or phosphorous have been of considerable interest during the past decades as extremely effective media for fiber lasers for the spectral region $1.0-1.1 \mu \mathrm{m}$ when pumped at 0.9 $1.0 \mu \mathrm{m}$ wavelengths. A variety of diode-pumping configurations (core and cladding) and pump wavelengths were extensively examined so far which resulted in recognition of optimal arrangements for multi-watt release from YF based lasers with high optical efficiency $\sim 70$ $75 \%$ and perfect beam quality $[1,2]$. However, in spite of remarkable progress in the field, there remain certain obstacles that limit the performance of YF based lasers, one of them being the photodarkening (PD) effect [3], i.e. long-term (minutes to hours) degradation of laser power from units to tens $\%$. This hardly mitigated disadvantage becomes notable when dealing with a laser based on heavily-doped $\mathrm{YF}$ where high $\mathrm{Yb}^{3+}$ population inversion is created, either at high-power continuous-wave or moderate-power pulsed lasing. A number of studies during the past years were aimed to understand the PD phenomenon which has remained unclear, although a few hypotheses have been proposed for its explanation [4-12]. Meanwhile, on one hand, the characterization procedures have been specified to quantify the PD phenomenon in YFs $[9,10]$, allowing a proper choice among YFs for a certain application. And on the other hand, some ways to enhance resistance of YFs to PD or at least to minimize its consequences have been suggested $[13,14]$.

In the meantime, a few studies aimed at the characterization of susceptibility of YFs having different chemical compositions under such irradiations as x-rays, $\gamma$ quanta, and UV have been reported recently [15-17]. The main motivation for these works was an inspection of resistance of YF employed in telecommunications and space technologies to harmful environments. In many cases, the excess loss spectra induced in YFs resemble the ones, characteristic for $\mathrm{PD}$ at resonant pumping into $\mathrm{Yb}^{3+}$ resonant-absorption $(0.9 \mu \mathrm{m}-1.0 \mu \mathrm{m})$ band. This interesting fact undoubtedly deserves attention and verification by an experiment where YF would be subjected to other types of irradiation (say, by high-energy electrons) and the result of this be directly compared with the $\mathrm{PD}$ consequences in the same YF.

Here we report on two sets of experiments where susceptibility of YFs with similar alumino-germano $(\mathrm{Al}, \mathrm{Ge})$ silicate glass core but with different $\mathrm{Yb}^{3+}$ ions' concentrations is inspected under irradiation either by an electron beam or by resonant (into $\mathrm{Yb}^{3+}$ resonant band) optical pumping. For both circumstances, qualitatively similar trends are revealed: Strong and monotonous changes in attenuation loss of the fibers in VIS (darkening) accompanied by more complex transformations (an initial decrease followed by increase) within the resonant ab- 
sorption band of $\mathrm{Yb}^{3+}$ ions upon dose (the case of electron irradiation) or time (the case of optical pumping at 977-nm wavelength). However, these trends are shown to be peculiar in details. Below, we compare and discuss the experimental data obtained and propose preliminary explanations.

\section{Experimental Arrangement}

\subsection{Fibers Characterization}

YFs inspected in these experiments were drawn from $\mathrm{Al}, \mathrm{Ge}$ co-doped silicate glass preforms fabricated using the MCVD and solution-doping processes. The atenuation spectra in a pristine (as-received) state of the fibers are shown in Figure 1(a). The concentrations of $\mathrm{Yb}^{3+}$ ions through a set of these YFs differed by more than an order of magnitude, so there were expected differences in the consequences of electron irradiation (further-e-irradiation) and optical pumping at $977 \mathrm{~nm}$ wavelength (further- $O P$ ) on the fibers' posterior properties. The fiber samples, having correspondingly the lowest, the intermediate, and the highest $\mathrm{Yb}^{3+}$ doping level, are referred further to as $Y F-1, Y F-2$, and $Y F-3$.

\subsection{Experimental Methods}

A controllable linear accelerator of the LU type which sources mono-energetic $(\sim 6 \mathrm{MeV})$ electrons was used in experiments where a pulsed $(\sim 5-\mu s)$ e-irradiation mode has been realized. The experiments were conducted at room temperature. YF samples were irradiated by placing them in the accelerator chamber during various time intervals, which provided growing irradiation doses. In-

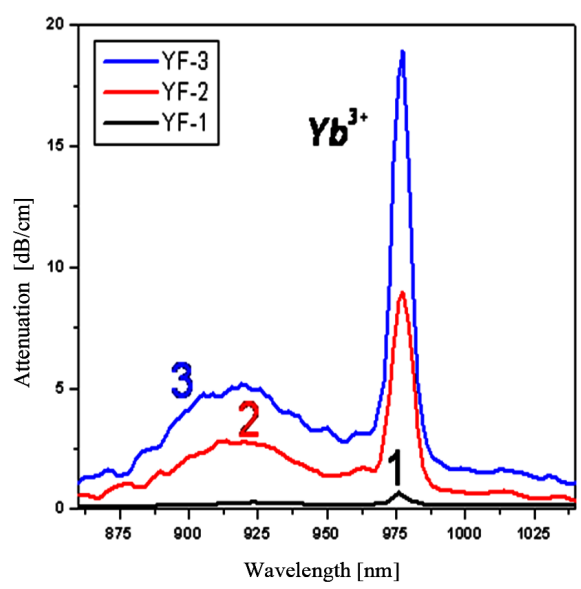

(a) dices " 1 ", " 2 ", and " 3 " label, on some of the figures below, doses $2 \times 10^{12}, 1 \times 10^{13}$, and $5 \times 10^{13} \mathrm{~cm}^{-2}$, respectively. The irradiated fibers were leaved for 10 days in advance to the measurements to avoid possible shortliving instabilities in the host glass, known for the fibers containing $\mathrm{Al}$ and Ge. Notice that ionization, i.e. the production of irradiation-excited carriers by an electron beam within a fiber's volume, plays the main role in the spectral transformations being reported. This is because high-energy primary electrons are virtually non-dissipating at the propagation through the fibers with an outer diameter of $125 \mu \mathrm{m}$. Meanwhile, some contribution in ionization might be produced by $\gamma$-quanta born at inelastic scattering of high-energy electrons propagating through the host glass.

Experiments on OP of YF at $977 \mathrm{~nm}$ were made by a similar way as described in Ref. [8]. YF samples were pumped using a standard $300 \mathrm{~mW} 977 \mathrm{~nm}$ laser diode (LD). The pump light was launched from the LD to SMF-28 fiber through a splice and then through one more splice to an YF sample. The end of the latter was spliced to another piece of SMF-28 fiber that was connected to an optical spectrum analyzer (OSA) for the transmission spectra measurements. In these experiments, we dealt with short pieces of YFs, of a cm range, to ensure no-lasing conditions and negligible contribution of amplified spontaneous emission of $\mathrm{Yb}^{3+}$.

The optical transmission spectra of the YF samples were obtained using a white-light source with a fiber output and the OSA turned to a $1 \mathrm{~nm}$ resolution. These spectra were recorded for a spectral range $400 \mathrm{~nm}-1200$ $\mathrm{nm}$, where the most interesting spectral transformations occur as the result of e-irradiation or OP. The output of the white-light source was spliced to a fiber set containing

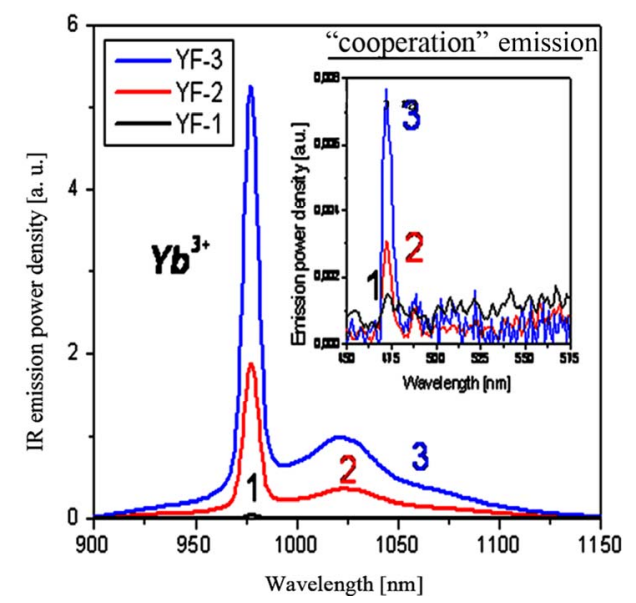

(b)

Figure 1. (a) Attenuation (small-signal absorption) spectra of fibers with low (YF-1), intermediate (YF-2), and high (YF-3) Yb $^{3+}$ contents: curves 1, 2, and 3, respectively; (b) Fluorescence spectra of the fibers at resonant 977 nm excitation (pump power-300 $\mathrm{mW}$ ). Labeling of curves 1, 2, and 3 is the same as in figure (a). Inset in figure (b) shows "cooperative" fluorescence in VIS. 
an YF sample (pristine or subjected to e-irradiation or to OP) and white-light attenuation within the sample was recorded using the OSA. The attenuation spectra were recorded before (using pristine samples) and after each stage of e-irradiation ("doses") or OP at $977 \mathrm{~nm}$ pumping ("times"). Lengths of the fiber samples were chosen to be short enough, from less than $1 \mathrm{~cm}(\mathrm{YF}-3)$ to tens of $\mathrm{cm}$ (YF-1), to provide the final spectra free of spectral noise artifacts. We measured the attenuation spectra from VIS to near-IR, i.e. within the range where the main spectral transformations resulting from e-irradiation or OP occur. In some of the figures below, the difference spectra are demonstrated which were obtained after subtraction of the attenuation spectra of pristine samples from the ones taken after some dose (time) of e-irradiation (OP). This allows insight to the net spectral loss resulting from the fibers darkening. All the spectra presented below have been obtained after formal recalculating transmission coefficients in losses $[\mathrm{dB} / \mathrm{cm}]$.

We also measured fluorescence spectra and fluorescence kinetics of $\mathrm{Yb}^{3+}$ before and after e-irradiation or after OP of the fibers, applying the lateral detecting geometry [18]. Fluorescence emission was collected from surface of an YF sample at the point spaced by approximately $5 \mathrm{~mm}$ from its splice with an output fiber of the LD. We used the same OSA for the fluorescence spectra measurements and a Ge photo-detector and oscilloscope for the fluorescence decay measurements. In the last case, LD power was modulated by a driver controlled by a function generator's signal to achieve square-shaped pulses with sharp rise and fall edges. The time resolution of the entire experimental setup was approximately $8 \mu$ s.

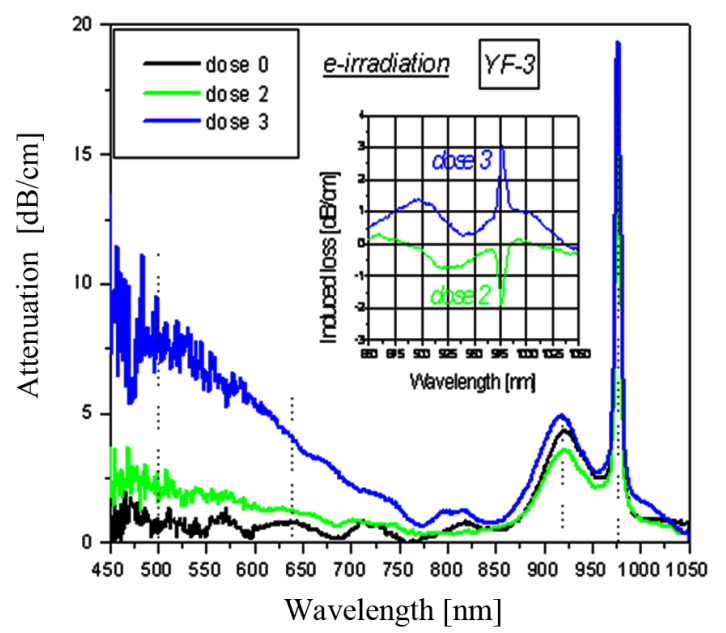

(a)

\section{Experimental Results}

\subsection{E-irradiation experiments}

The results of these experiments are highlighted by Figures 2, 3, 4(a)-(b) and 7.

The attenuation spectra of samples YF-3 and YF-1, having correspondingly the highest and lowest $\mathrm{Yb}^{3+}$ concentrations, after different doses of e-irradiation along with the attenuation spectra of the samples in a pristine (dose "0") state are shown in Figure 2(a)-(b).

First, a notable increase of background loss in the fibers in VIS with increasing e-irradiation dose is revealed from Figure 2 (see main frames). Also notice a specific spectral character of this loss for both fibers, that is, a drastic rise of its magnitude towards shorter wavelengths. This is a trend well-known for the experiments on influence of various-type irradiations upon optical properties of $\mathrm{Yb}^{3+}$-free silica fibers. At the same time, the apparent differences are seen in magnitude of e-irradiation induced loss in these two samples, i.e. a much higher level of darkening in YF-3 than in YF-1. [The data for sample YF-2, intermediate in $\mathrm{Yb}^{3+}$ doping level, demonstrate similar but intermediate growth of the background loss in VIS as compared to samples YF-3 and YF-1.]

Second, definitive but less pronounced spectral transformations are revealed for the resonant-absorption band of $\mathrm{Yb}^{3+}(850-1100 \mathrm{~nm})$; see insets to Figures 2(a)-(b). The insets show the difference spectra obtained as it is described in Section 2. Vastly small in sample YF-1 (Fig. ure 2(b)), the spectral transformations become significant in sample YF-3 (Figure 2(a)) and they have a complex

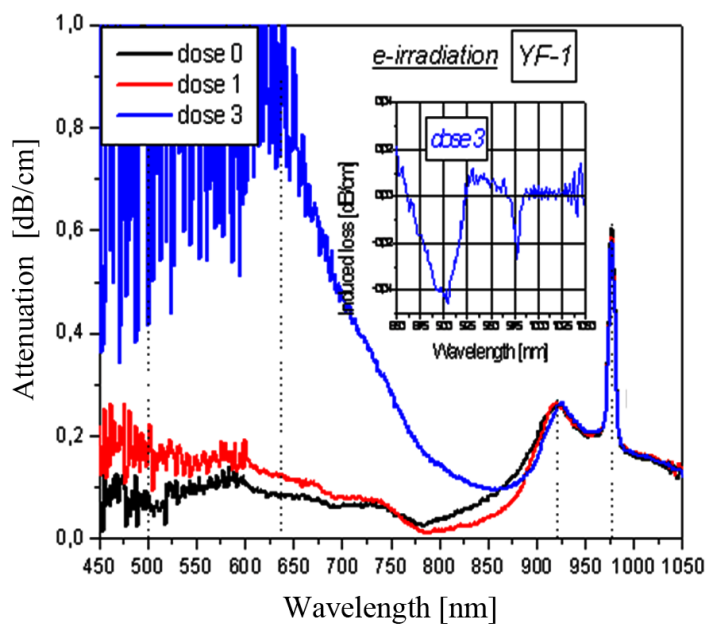

(b)

Figure 2. Attenuation spectra of samples YF-3 (a) and YF-1 (b). The data are for e-irradiation doses increased from " 0 " (pristine samples) through " 1 " and " 2 " to " 3 ". Insets show the difference spectra obtained after subtraction of the spectra of pristine samples from the ones after e-irradiation of the samples. Dashed lines schematically show the positions of wavelengths for which the data in Figure 3 are built. 
character regarding e-irradiation dose growth: Compare the difference spectra obtained after doses " 2 " and " 3 ". The revealed behavior seems to be a consequence of some process associated with e-irradiation which affects the concentration of $\mathrm{Yb}^{3+}$ ions.

More details are seen from Figure 3 where we plot the results obtained for samples YF-1 (a) and YF-3 (b), taken from the whole set of e-irradiation doses. Figures 3 (a)-(b) demonstrates how attenuation within the resonant- absorption of $\mathrm{Yb}^{3+}$ (peaks at 920 and 977 nm, see also Figure. 1(a)) changes through e-irradiation: See curves 1 (for the $977 \mathrm{~nm}$ peak) and curves 2 (for the 920-nm peak), respectively. A decrease followed by increase of the magnitude of small-signal absorption coef ficient arises in both peaks with increasing e-irradiation dose in YF-3 (heavier doped with $\mathrm{Yb}^{3+}$ ); notice that this behavior is much less expressed in YF-1 (lower doped with $\mathrm{Yb}^{3+}$ ).

For comparison purposes, we also plot in Figure 3 the changes in attenuation of samples YF-3 (c) and YF-1 (d)

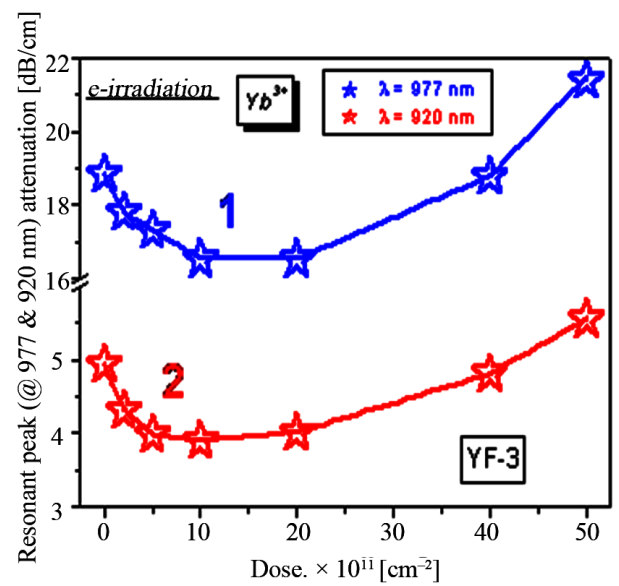

(a)

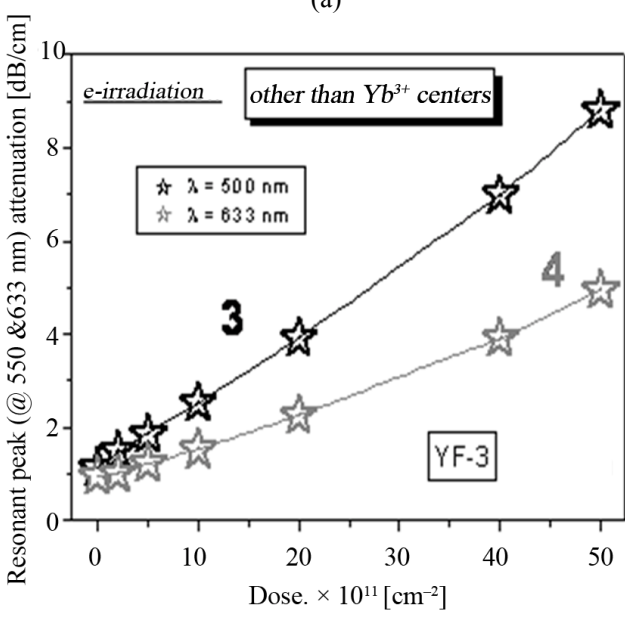

(c) in VIS where background (non-resonant) losses arise as the result of e-irradiation. Here we limit ourselves by giving the data for a couple of wavelengths in VIS, at 500 (curve 3) and 633 (curve 4) nm. It is seen that background loss monotonously (almost linearly) grows with e-irradiation dose, a common effect for silica based fibers. Importantly, the rate of growth is higher in YF-3 than in YF-1. Furthermore, it deserves attention that an initial level of background loss in pristine YF samples correlates with an initial content of $\mathrm{Yb}^{3+}$ ions. [The data for sample YF-2 are similar to the ones shown in Figure 3 for samples YF-3 and YF-1, but the magnitude of spectral transformations in YF-2 is intermediate when comparing those in YF-3 and YF-1.]

In Figures 4(a) and (b), we gather the experimental results from Figures. 2 and $\mathbf{3}$ for samples YF-1 and YF-3 and add the data for sample YF-2. This allows seeking the concentration dependences of the resonant $\left(\mathrm{Yb}^{3+}\right)$ and background loss induced in the fibers at e-irradiation upon

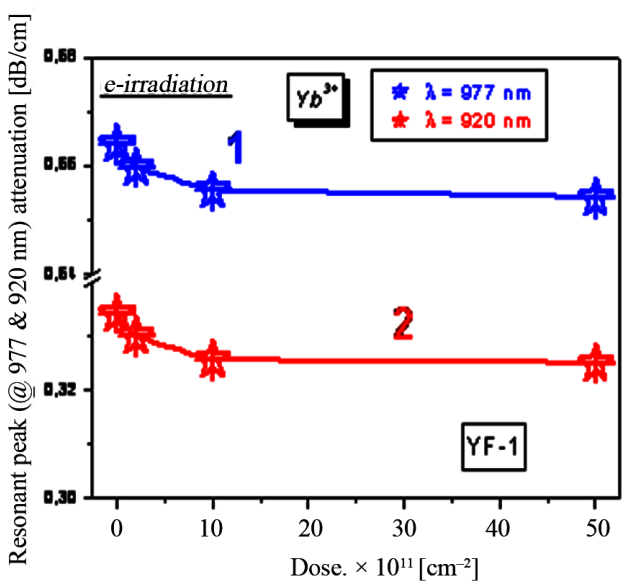

(b)

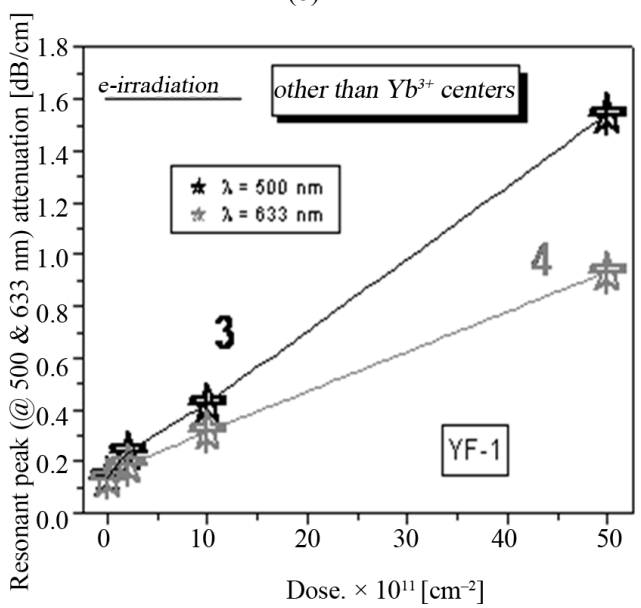

(d)

Figure 3. Dose dependences of attenuation in resonant-absorption $\mathrm{Yb}^{3+}$ peaks centered at 977 (curves 1) and 920 (curves 2 ) nm (top panels) and in VIS, for wavelengths 500 (curves 3) and 633 (curves 4) $\mathbf{n m}$ (bottom panels). The data are for samples YF-3 (a, c) and YF-1 (b, d). 


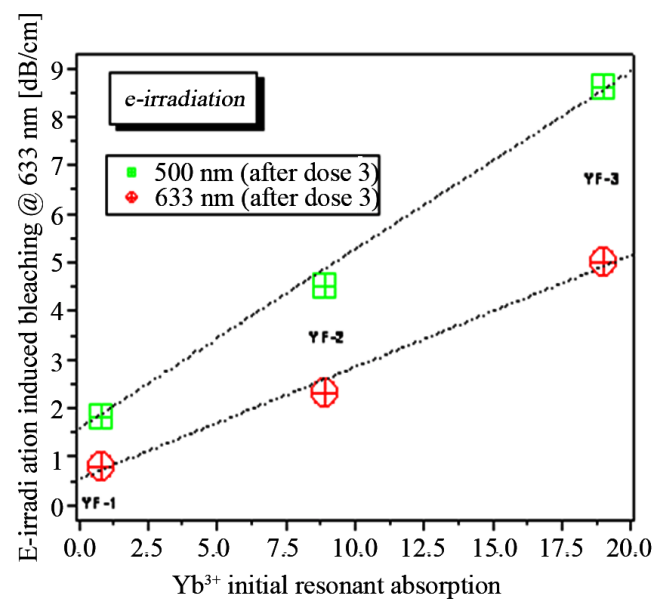

(a)

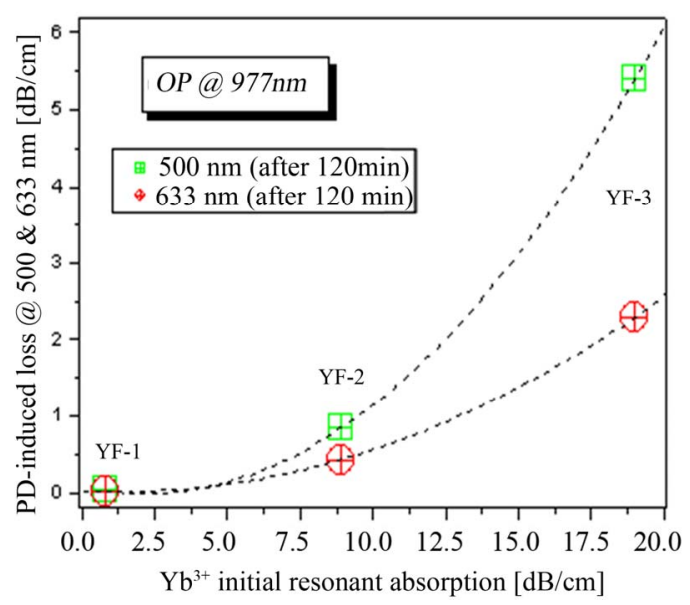

(c)

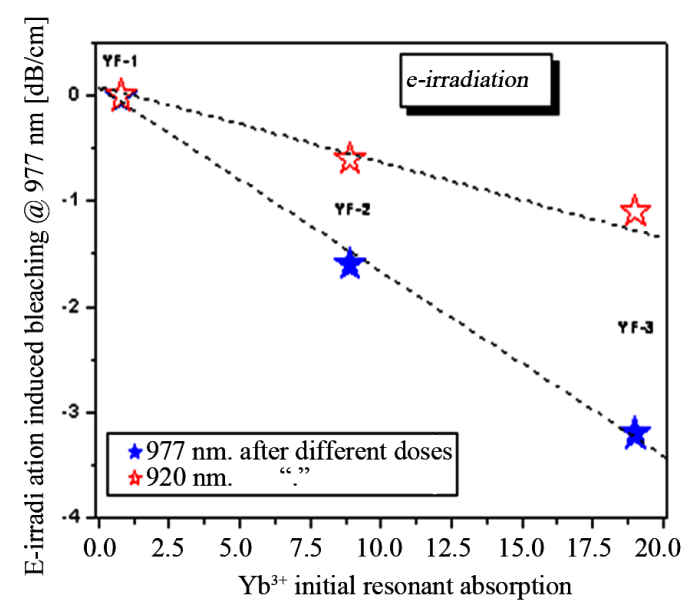

(b)

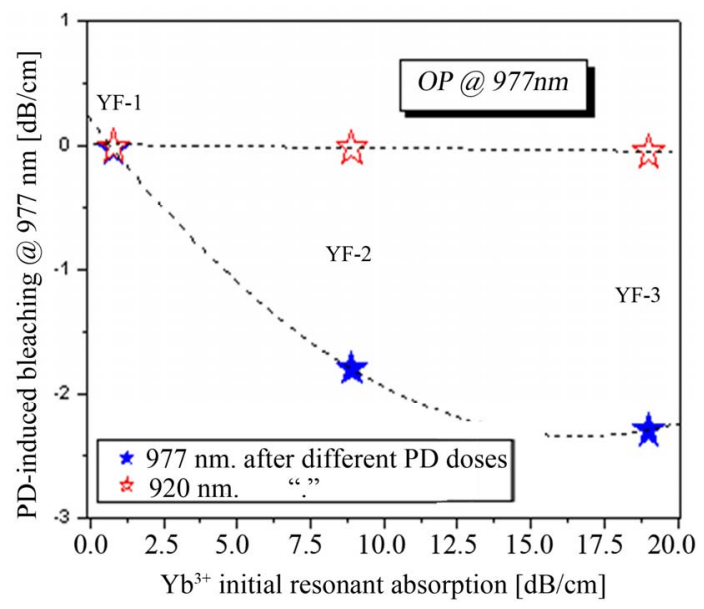

(d)

Figure 4. The results of experiments with fibers YF-1, YF-2, and YF-3, which were obtained for different e-irradiation doses (a, b) and OP times (c, d). The data are for the resonant-absorption peaks at 977 and $920 \mathrm{~nm}$ (filled and empty asterisks) (b, d)) and for the VIS region, exampled by wavelengths $500 \mathrm{~nm}$ (crossed squares) and $633 \mathrm{~nm}$ (crossed circles) (a, c). Dotted lines are for visual purposes only.

the value of small-signal absorption coefficient at $977 \mathrm{~nm}$. From Figure 4(a), one can first reveal a monotonic increase of background (non-resonant) loss in VIS (darkening), exampled by wavelengths 500 and $633 \mathrm{~nm}$, with increasing $\mathrm{Yb}^{3+}$ concentration, in turn proportional to $\mathrm{YF}$ small-signal absorption at $977 \mathrm{~nm}$. This demonstrates that the presence of $\mathrm{Yb}^{3+}$ dopants in the fibers gains their degradation at e-irradiation. Here we show the results obtained for e-irradiation dose " 3 " only since for the other doses the dependences are similar, given by a monotonic dose dependence of the induced loss in VIS (refer e.g. to Figures 3 (c)-(d)).

Then, from Figure 4(b) it is seen that the lowest levels, to which the values of the resonant absorption in the 977 $\mathrm{nm}$ peak approach through e-irradiation (minima of curves 1 in Figure 2), decrease with increasing $\mathrm{Yb}^{3+}$ concentration through a set of samples YF-1, YF-2, and YF-3. A similar trend is observed for the other peak of $\mathrm{Yb}^{3+}$ (at $920 \mathrm{~nm}$ ). This fact seems to be in favor of that initial concentration of $\mathrm{Yb}^{3+}$ ions in pristine samples substantially decreases as the result of e-irradiation (at its primary stage). However, it should not be overlooked that at the following stages of e-irradiation $\mathrm{Yb}^{3+}$ concentrations are re-established on the levels comparable with those in pristine YFs (refer to Figure 3(a)).

The remainder of Figure 4, graphs (c) and (d), gives the results obtained in the experiments on spectral transformations in YFs at OP which are reported in the next sub-section.

\subsection{OP experiments}

The results of these experiments are highlighted by Figures 4(c)-(d) and Figures 5-8. 
We limit ourselves by reporting here the results of OP experiments for sample YF-3 mainly (see Figures 5-7 below), having the highest content of $\mathrm{Yb}^{3+}$ ions in a pristine state. Meanwhile, we summarize all of the results (for samples YF-1, YF-2, and YF-3) in Figure 4(c)-(d).

Figure 5 shows the attenuation spectra of sample YF-3 (having a short length of $0.8 \mathrm{~cm}$ ) after 40 and 120 min. of OP. LD power was fixed in these experiments at approximately $300 \mathrm{~mW}$, providing the highest attainable level of $\mathrm{Yb}^{3+}$ population inversion. For comparison, the

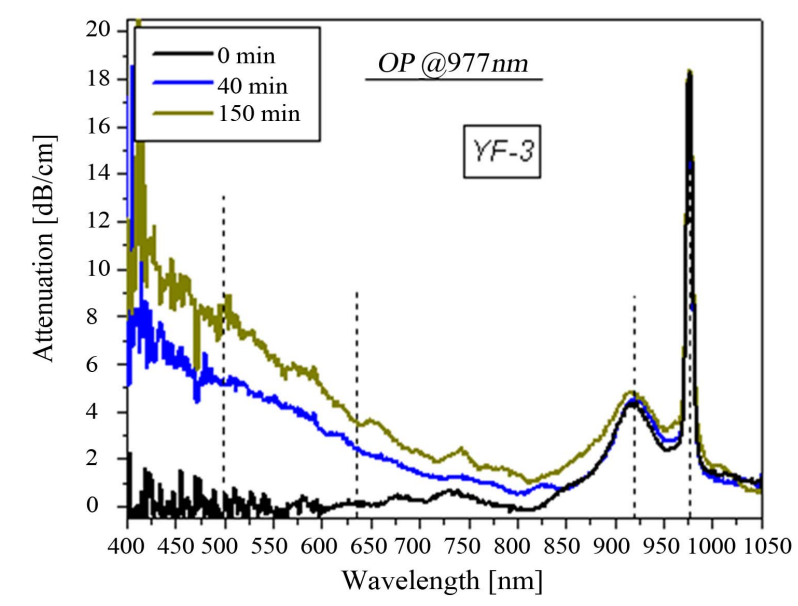

Figure 5. Attenuation (small-signal absorption) spectra of fiber sample YF-3 after OP @ 977 nm. The data are for a pristine sample (curve 1: “0 min") and for photo darkened samples (curves 2 and 3, obtained after 40 and $150 \mathrm{~min}$ of $O P$, respectively). Dashed lines show the positions of wavelengths for which the data in Figure 6 are built.

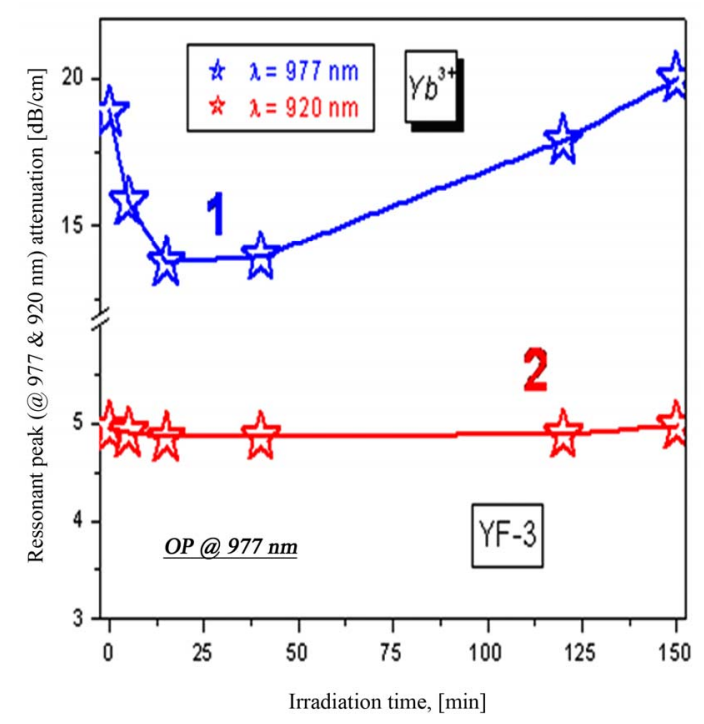

(a) attenuation spectrum of a pristine $(0 \mathrm{~min})$ sample YF-3 is shown in Figure 5, too. Once compared with the atenuation spectra after e-irradiation (refer to Figure 2(a)), these spectra are seen to be similar in appearance. That is,a substantial increase of background loss arises in VIS with increasing OP time (the PD effect). Notice that the spectral signature of PD resembles the one at darkening after e-irradiation (refer to Figure 2). The spectral changes that occur within the resonant $\left(\mathrm{Yb}^{3+}\right)$ absorption band at PD of are discussed below; see Figure 7.

In Figure 6(a), we demonstrate the results of the experiments with sample YF-3, obtained at increasing OP time. Their representation is similar to the one used at the description of experiments on e-irradiation, see Figure 3(a). From Figure 6(a), it is seen how attenuations in the two absorption peaks of $\mathrm{Yb}^{3+}$ ions (at 977 and $920 \mathrm{~nm}$ ) change through OP; see curves 1 and 2, respectively. The time dependence of OP induced changes at $977 \mathrm{~nm}$ resembles the dose dependence at e-irradiation of sample YF-3 (see curve 1 in Figure 3(a)). However, curve 1 in Figure 6(a) has an "asymmetric" shape versus OP time, differing from a "symmetric" shape of the dose dependence at e-irradiation given by curve 1 in Figure 3(a). Furthermore, the time dependence of OP induced changes at $920 \mathrm{~nm}$, see curve 2 in Figure 6(a), is seen to be very weak, being completely different from curve 2 in Figure 3(a) (e-irradiation). Therefore, we can propose that somewhat different mechanisms are involved in these two (e-irradiation and OP) treatments of the fibers which are responsible for the induced changes within the resonant-absorption band of $\mathrm{Yb}^{3+}$ at 977 and $920 \mathrm{~nm}$.

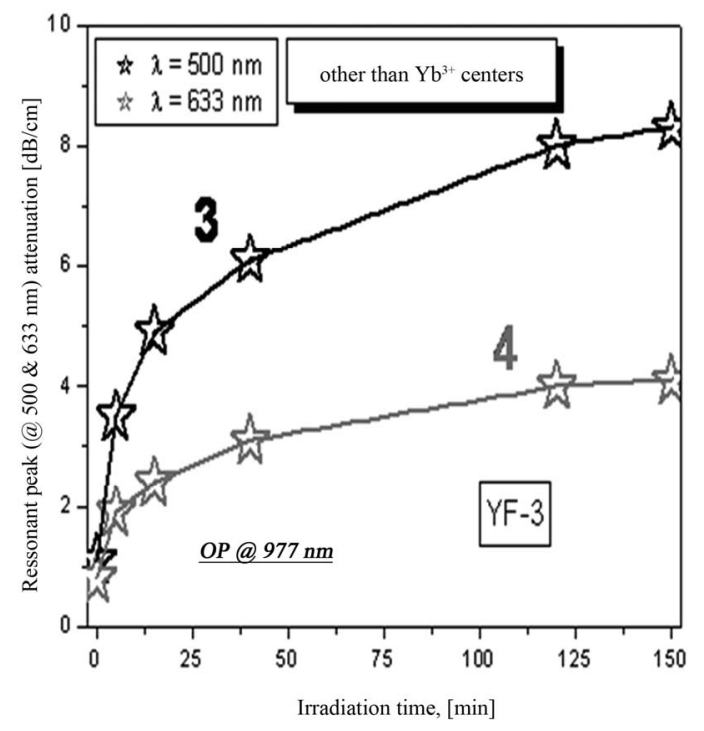

(b)

Figure 6. Dose dependences of attenuation in resonant-absorption $\left(\mathrm{Yb}^{3+}\right)$ peaks centered at 977 (curve 1) and 920 (curve 2) nm (a) and in VIS, for wavelengths 500 (curve 3) and 633 (curve 4) nm (b). The data are for sample YF-3. 
In Figure 6(b), we demonstrate the results of all of the spectral transformations that occur in sample YF-3 in VIS, where non-resonant background loss arises as the result of OP. This can be also seen by referring to Figure 5 and compared with the results of e-irradiation shown in Figure 3(c). Again, we provide in Figure 6(b) the data for a couple of wavelengths only, 500 (curves 3 ) and 633 (curves 4) nm, as the representatives. In contrast to the dose dependences at e-irradiation, long-term OP at the resonant wavelength $977 \mathrm{~nm}$ results in completely different dynamics of background loss with time. Indeed, it is essentially nonlinear in time: There is a short time interval in the beginning (few minutes) where PD increases dramatically while in the remainder of OP (tens of minutes) PD slows down and tends to saturate. Note that the described time dependences are very similar to the ones commonly met at PD experiments with YFs at $633-\mathrm{nm}$ probing (a He-Ne laser).

Let's now consider the results shown in Figures 7 and 8 where we make insight to the difference spectra.

Figure 7 allows a direct comparison of the attenuation spectra for sample YF-3 after dose " 3 " of e-irradiation (curve 1) and after 2 hours of OP (curve 2). The spectra look qualitatively similar which could validate the mechanisms that stand behind the spectral transformations to be basically similar. At the same time, if one spectrum is formally subtracted from another, the result (curve 3 in Figure 7) shows a definitive difference. That is, apart from the difference in the background loss which ought to be present in anyway, there is a feature within the $\mathrm{Yb}^{3+}$ resonant band: Although no deviation from a "plain" behavior of curve 3 is seen nearby $920 \mathrm{~nm}$ peak of $\mathrm{Yb}^{3+}$, there is a well-pronounced $977 \mathrm{~nm}$

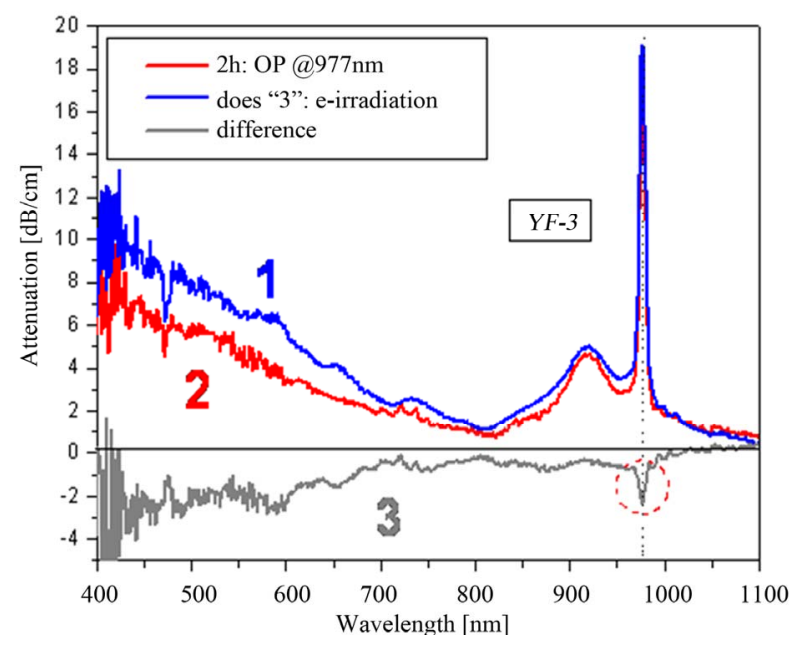

Figure 7. Difference attenuation spectra after dose " 3 " of e-irradiation (curve 1) and after 2 hours of OP at $977 \mathrm{~nm}$ (pump power is $300 \mathrm{~mW}$ ) (curve 2); curve 3 is the difference of spectra 1 and 2 . The data are for sample YF-3. peak (it is marked by a dotted ring on Figure 7). This detail seems to be important because it lightens nonhomogeneity within the $\mathrm{Yb}^{3+}$ resonant-absorption band nearby $977 \mathrm{~nm}$, present at long-term OP but not-at e-irradiation of the fiber.

This becomes more apparent when an analysis of the results of OP-induced PD of the other samples, YF-1 and YF-2, has been made. Indeed, from Figures 8 (a)-(b), where we plot the difference spectra obtained for these fibers, a firm spectral detail is seen to appear exactly within the $977 \mathrm{~nm}$ peak of $\mathrm{Yb}^{3+}$ ions (it is marked by a dotted ring in plots (a) and (b)). This fact can be interpreted as follows: At OP-induced PD, that is, at rising of background loss tailing from VIS towards near-IR (see the left part of Figures 8(a)-(b)), drastic decreasing of the resonant absorption occurs within a narrow $977-\mathrm{nm}$ peak. Some more assertions on this feature are made in the Discussion section.

In Figures 4(c)-(d), we gather the results of OP experiments for an entire set of YF samples, seeking the concentration dependences of the resonant (within the $\mathrm{Yb}^{3+}$ band) and background non-resonant spectral transformations.

In contrast to the results of e-irradiation (refer to Figures 4(a)-(b)), one can firstly reveal essentially nonlinear growth of background loss at wavelengths 500 and $633 \mathrm{~nm}$ with increasing $\mathrm{Yb}^{3+}$ concentration (Figure 4(c)). Obviously, it is different from linear growth of background loss at e-irradiation of the fibers (Figure 4(a)). Secondly, it is seen that instead of a linear decrease of resonant absorption peaks at 977 and $920 \mathrm{~nm}$ with dose, occurring at primary stages of e-irradiation (see Figure 4(b)), a strongly nonlinear law is seen to fit a decrease of the resonant absorption peak at $977 \mathrm{~nm}$ while almost no change to be present at $920 \mathrm{~nm}$; see Figure 4(d).

Hence, the situation with OP induced spectral transformations in our YFs is more complex and curious at first glance. The $977 \mathrm{~nm}$ peak is strongly affected by OP, not the $920 \mathrm{~nm}$ one. This can be explained by the presence in the fibers of centers others than $\mathrm{Yb}^{3+}$ dopants, but closely related to them and spectrally matching them nearby $977 \mathrm{~nm}$. Moreover, partial weight of such centers in YF core ought to increase with increasing $\mathrm{Yb}^{3+}$ ions concentration. The nonlinear behavior of non-resonant background loss versus OP time, revealed above (see Figure 6(b)), seems to be a closely related phenomenon.

It should be noted that at further exposure of YFs to OP an initial state of the resonant absorption peaks tends to restore (Figure 6(a)), thus demonstrating the behavior quite similar to e-irradiation of the fibers (Figure 3(a)).

\subsection{Fluorescence Measurements}

The fluorescence spectra obtained for pristine samples 


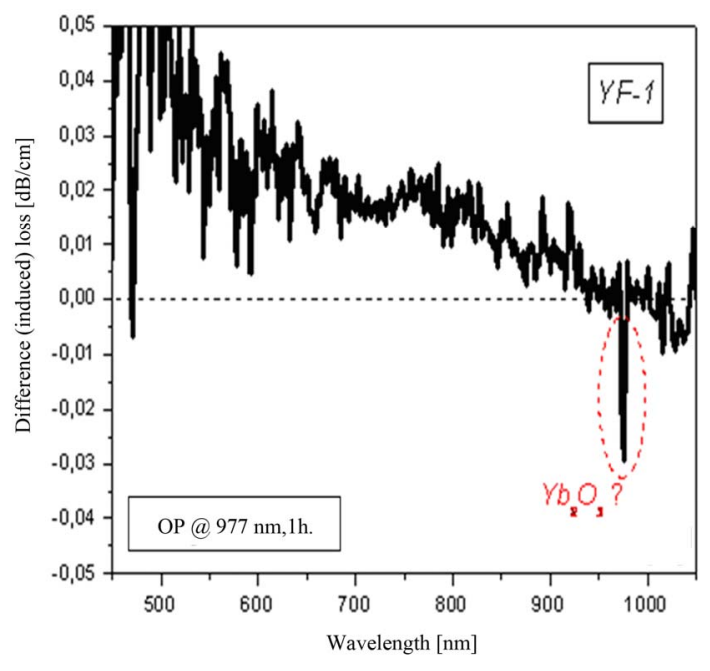

(a)

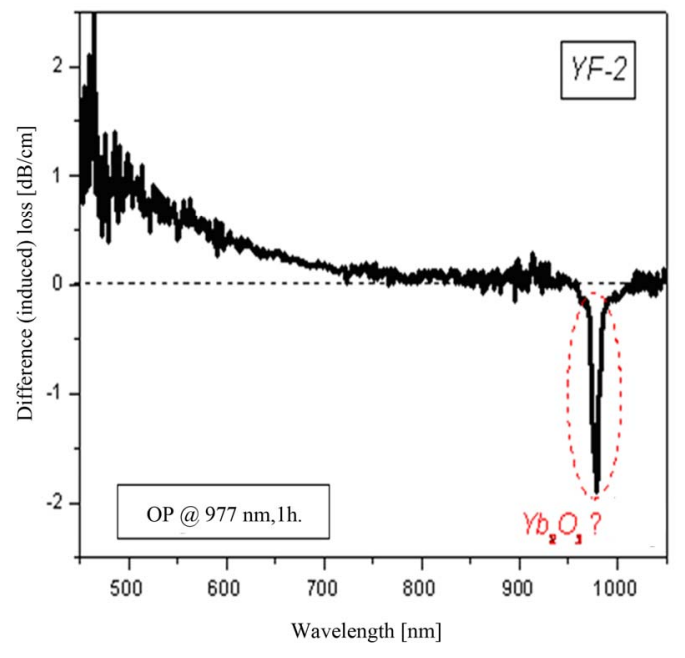

(b)

Figure 8. Difference (loss) spectra of samples YF-1 (a) and YF-2 (b), obtained after 1-hour of OP at 977 nm (pump power is $300 \mathrm{~mW})$.

YF-1, YF-2, and YF-3 at 977-nm pumping are shown in Figure 1(b). All of these are similar in appearance and their intensities are proportional to concentrations of $\mathrm{Yb}^{3+}$ in the fibers. [The measurements were made at the same conditions and for same pump powers.]

We also measured the fluorescence spectra of the fibers after irradiation by an electron beam or after long-term OP at $977 \mathrm{~nm}$, but we couldn't capture any qualitative spectral change within the $\mathrm{Yb}^{3+}$ fluorescence band; so, we don't provide them here. We could only see a small decrease in the fluorescence intensity as the result of irradiations but obviously this trend could not be quantified.

For the fluorescence decays measured at modulated pumping of the YFs, it was found that the characteristic $\mathrm{Yb}^{3+}$ fluorescence decay time slightly decreases through the set of pristine YF samples. This is a result of the presence of two exponents in the fluorescence kinetics measured by $\sim 0.7 \mathrm{~ms}$ (main) and $\sim 0.2-0.3 \mathrm{~ms}$ ("auxiliary"). Notice that insignificant growth of the latter contribution was detected for the fiber with the highest $\mathrm{Yb}^{3+}$ content (YF-3); see also Refs. [18-20]. However, the time constants obtained for fitting the decays were found to be non-affected neither after e-irradiation nor after long-term OP. A lone novelty found was that both the treatments gave rise to growth of scattering in the fibers at the pump wavelength. This extra scattering looked as an instantaneous (within the resolution limit of $8 \mu \mathrm{s}$ ) drop of a signal from the photo-detector, followed by slow $\mathrm{Yb}^{3+}$ fluorescence decay. Since such a scattering signal was virtually not present in pristine samples, this observation might deserve attention.
Concluding, we can reveal that none, or vastly small, changes occurred with our YFs in the sense of $\mathrm{Yb}^{3+}$ fluorescence properties.

\section{Discussion}

\subsection{Interpretation of Experimental Results}

Summarizing all the data reported in Section 3, we notice that either at e-irradiation or at resonant OP of YFs substantial and complex but different in appearance changes arise within the resonant absorption band of $\mathrm{Yb}^{3+}$ ions ("reversible bleaching") while monotonous growth of non-resonant background loss occurs in VIS ("darkening"). Furthermore, these trends are revealed to originate from the changes in concentrations of $\mathrm{Yb}^{3+}$ ions and seemingly of other centers, closely related to them and spectrally matching them nearby $977 \mathrm{~nm}$. This is the main result of our experiments. In the meantime, in virtue of importance of the details figured out above a few more assertions can be made.

A general consequence of the experiments on e-irradiation, a rise of background non-resonant loss in YFs in VIS (see Figures 3(c)-(d)), is not surprising. This loss correlates by a spectral signature with the excess loss that arises in optical fibers after other types of irradiation (x-rays, $\gamma$ quanta, UV [15-17]). Some other aspects are as follows:

(1) A monotonic increase of the background loss in VIS (darkening) with increasing $\mathrm{Yb}^{3+}$ content in the YFs which demonstrates, as it was already mentioned, that the presence of $\mathrm{Yb}^{3+}$ dopants leads to a higher degree of 
degradation of the fibers at e-irradiation; see Figure 4(a);

(2) A notable decrease followed by equally notable increase that arise in the resonant-absorption peaks of $\mathrm{Yb}^{3+}$ (at 920 and $977 \mathrm{~nm}$ ) with increasing e-irradiation dose (Figure 3(a)-(b)), the effect also dependent on $\mathrm{Yb}^{3+}$ concentration; see Figure 4(b).

Thus, the presence of $\mathrm{Yb}^{3+}$ dopants in the fibers results in a more pronounceable degradation as the result of e-irradiation, with a probable reason being that $\mathrm{Yb}^{3+}$ ions are powerful sources of secondary carriers (electrons and holes) born at e-irradiation. That is, the changes within the resonant-absorption band of $\mathrm{Yb}^{3+}$ may stem from e-irradiation induced excitation of inner-shell $(f)$ electrons of $\mathrm{Yb}^{3+}$ and their valence transformation through the charge-transfer (CT) processes (direct and return), sketched by the following reactions $[8,21]: e^{-}+Y b^{3+} \rightarrow$ $Y b^{2+} ; e^{+}+Y b^{2+} \rightarrow Y b^{3+}$, where $\mathrm{e}^{-}$and $\mathrm{e}^{+}$are the notations for secondary (irradiation induced) electrons and holes and $\mathrm{Yb}^{2+}$ is the notation for Ytterbium ions in valence-two state. In turn, the presence in the fibers of secondary carriers as the result of e-irradiation can cause formation of such defects as oxygen-deficit (ODC) and non-bridging oxygen-hole (NBOHC) centers [19,22]. These centers are known to be responsible for the wide excess-loss spectral bands similar to the ones formed in our darkened fibers; see Figures $\mathbf{2}$ and $\mathbf{7}$.

(2) Qualitatively similar observations can be made regarding the spectral transformations in the YFs as the result of OP at $977 \mathrm{~nm}$; refer to Figures 4(c)-(d) and Figures 5-8.

Analogously, the following trends are revealed:

(3) Background loss in VIS significantly grows at long-term OP (see Figures 5 and 6(b)) and its character is typical for the PD effect in YFs [3-13]. At the same time, an increase of this loss in VIS with increasing small-signal absorption has, in contrast to e-irradiation, a strongly nonlinear law (see Figure 4(c)), thus revealing an almost quadratic dependence versus $\mathrm{Yb}^{3+}$ concentration in the fibers [23];

(4) The dependences of resonant absorption, measured in the peaks of $\mathrm{Yb}^{3+}$ at 977 and $920 \mathrm{~nm}$ upon OP time, have essentially different characters (see Figure 6(a)). If the absorption coefficient in the $977 \mathrm{~nm}$ peak changes by a law similar to the one at e-irradiation (a primary decrease followed by increase versus time), the absorption coefficient in the $920 \mathrm{~nm}$ peak is virtually constant through long-term OP. The concentration dependences shown in Figure 4(d) tell us more: The changes in these peaks with increasing content of $\mathrm{Yb}^{3+}$ ions in the fibers are also different. We cannot interpret these details in terms of simple concentration dependences with regard to $\mathrm{Yb}^{3+}$ ions. Otherwise, an assumption should be made instead that the changes in the $977 \mathrm{~nm}$ peak are related to the changes in concentration of some centers others than $\mathrm{Yb}^{3+}$ ions but spectrally matching them nearby the 977 $\mathrm{nm}$ peak;

(5) The spectral signature of the latter is seen from Figures $\mathbf{7}$ and 8 where the difference attenuation spectra after OP are presented. One can capture from Figures 7 and 8 that the PD effect (growth of non-resonant loss in VIS) is accompanied by bleaching of the resonant peak at $977 \mathrm{~nm}$ whereas none occurs with the peak at $920 \mathrm{~nm}$. Notice that a similar feature was reported earlier for other type of YF, fabricated by the DND method [8].

All the facts (3-5) being gathered together, tell us that $\mathrm{PD}$ in YF at high-power long-term OP at $977 \mathrm{~nm}$ occurs among the centers the concentration of which is a nonlinear (almost quadratic) function of $\mathrm{Yb}^{3+}$ ions concentration. These are most probably the centers composed of couples of $\mathrm{Yb}^{3+}$ ions ("pairs"). Furthermore, similar reactions: $e^{-}+Y b_{p}{ }^{3+} \rightarrow Y b_{p}{ }^{2+} ; e^{+}+Y b_{p}{ }^{2+} \rightarrow Y b_{p}{ }^{3+}$ (see above) can be written to address these transformations at $\mathrm{OP}$, where index $p$ stands to emphasize that a pair of $\mathrm{Yb}^{3+}$ ions is involved in the processes and notations $e^{-}$ and $e^{+}$are used for an electron and hole, free or trapped by the nearest ligand, say oxygen $[8,24]$. Such reactions can also go at the assistance of CT processes between ion pairs where both the constituents are in the excited state. Hence, the spectrally wide background loss (PD) in the fibers, see Figures 5 and 7, can stem from producing of $\mathrm{Yb}_{\mathrm{p}}{ }^{2+}$ and of $e^{-} / e^{+}$-related centers (say, ODC and $\mathrm{NBOHC}$ ) at OP like this takes place at e-irradiation.

It is currently believed that PD occurs among clusters of $\mathrm{Yb}^{3+}$ ions (obviously, pairs are their kind). However, a meaningful novelty found in the present study for the first time is the spectral feature, occurring at OP (see dotted rings in Figures $\mathbf{7}$ and $\mathbf{8}$ but not - at e-irradiation.

\subsection{Pre-concluding Remarks}

There are evidences for that the PD process can be associated with non-binding oxygen near surfaces of $\mathrm{Yb} / \mathrm{Al}$ clusters that can be formed in alumino-silicate glass (our case). The non-binding oxygen originates from $\mathrm{Yb}^{3+}$ substituting $\mathrm{Si}^{4+}$ sites. When subjecting an $\mathrm{YF}$ to $977-\mathrm{nm}$ $\mathrm{OP}$, the excess energy is radiated as phonons, causing a lone electron of a non-binding oxygen atom to shift to a nearest neighbour non-binding oxygen atom with creation of a hole and a pair of lone electrons, which results in a Coulomb field between the oxygen atoms to form an unstable "color" center. The conversion of such an unstable center to a semi-stable center requires the shifting of one electron of the lone electron pair to a nearest neighbour site [25]. As a result of this, the formation of $\mathrm{Yb}-$ (and probably Al-) related ODC can occur. On the other hand, PD in alumino-silicate YFs may take place 
through the breaking of ODC, which gives rise to release of free electrons. The released electrons may be trapped at $\mathrm{Al}$ or $\mathrm{Yb}$ sites to form a color center resulting in $\mathrm{PD}$. These hypotheses can serve as the arguments, bringing more clarity in understanding of similarity of the spectral transformations in YFs at e-irradiation (creation of "secondary" carriers in the core glass by an electron beam) and at OP (creation of carriers and color centers by the pump light).

II. Some more assumptions can be made in attempt to understand the PD phenomenon at OP. Of course, different "paired" complexes (say, Yb-O-Yb or more complicate clusters of such kind) can be thought to be involved at $\mathrm{PD}$, but we suggest here $\mathrm{Yb}_{2} \mathrm{O}_{3}$ "molecules" (or their agglomerates), the presence of which in YFs at increasing $\mathrm{Yb}^{3+}$ ions concentration is quite probabilistic [26]. It is also worth noting that CT transitions are well-known for $\mathrm{Yb}$-doped sesquioxides $\left(\mathrm{Yb}_{2} \mathrm{O}_{3}\right.$ is one of them) while these are still debated for single $\mathrm{Yb}^{3+}$ ions "dissolved" in YF core glass $[8,12,27,28]$. So, $\mathrm{Yb}_{\mathrm{p}}{ }^{3+}$ in the form of inherent centers $\mathrm{Yb}_{2} \mathrm{O}_{3}$, absorption spectrum of which matches well the spectral feature ringed in Figure 8, seem to be relevant candidates to explain PD: Refer e.g. to the works $[29,30]$ where the presence of the strong $977 \mathrm{~nm}$ peak and the absence (vanishing) of the 920-nm peak was revealed to be characteristic for $\mathrm{Yb}_{2} \mathrm{O}_{3}$ (see also Ref. [31] where the peaks at $977 \mathrm{~nm}$ from single and paired $\mathrm{Yb}^{3+}$ are shown to match spectrally). Furthermore, on one hand, the presence of cooperative VIS fluorescence at $977 \mathrm{~nm}$ excitation (see inset in Figure 1(b)) is typical for $\mathrm{Yb}_{2} \mathrm{O}_{3}$ [32], while on the other hand, $\mathrm{PD}$ was proved to be associated with the presence of cooperative processes in YFs [7,33]. (The spectral feature seen in Figure 1(b) in VIS is undoubtedly ascribed by us to the cooperative fluorescence of $\mathrm{Yb}^{3+}$ since no other spectral features were detected which would originate from traces of un-wanted rare-earth dopants [34,35] like $\mathrm{Tm}^{3+}$.)

One more assumption can be made that $\mathrm{Yb}_{2} \mathrm{O}_{3}$ is a typical defect center in the core glass network which can be formed at high $\mathrm{Yb}^{3+}$ concentrations. Probably, namely this "color" center, firstly detected yet in 1997 [36], is responsible for the presence of non-saturated (by $977-\mathrm{nm}$ radiation) resonant absorption in heavily $\mathrm{Yb}^{3+}$ doped fibers [18,36-38]. This non-saturated absorption can be understandable in virtue of extremely high absorption coefficient at $977 \mathrm{~nm}\left(\sim 1 \times 10^{-20} \mathrm{~cm}^{2}\right)$ and almost quenched fluorescence $(\sim 10 \mu \mathrm{s})$, characteristic for $\mathrm{Yb}_{2} \mathrm{O}_{3}$ centers $[28,32,39]$. Apparently, these values are completely incompatible with those known for single $\mathrm{Yb}^{3+}$ ions dissolved in the core glass: $\sim 1 \times 10^{-21} \mathrm{~cm}^{2}$ and $\sim 1 \mathrm{~ms}$, respectively; see e.g. Ref. [40]. Further, possible presence of $\mathrm{Yb}_{2} \mathrm{O}_{3}$ centers in heavily-doped $\mathrm{YF}$, which in- tensively absorb the pump light but are non-fluorescent ("quenched"), may cause an excessive temperature rise in YF core.

It is logical to bridge here to the papers $[41,42]$ where the idea of an intrinsic color center, like $\mathrm{Yb}_{2} \mathrm{O}_{3}$, has been proposed to address some of the concentration phenomena in heavily rare-earth doped materials. So, the physical essences given by doping $\mathrm{YF}$ with $\mathrm{Yb}_{2} \mathrm{O}_{3}$ (non-intentionally or intentionally [43]) can be of importance.

III. We didn't discuss above a possible role of the spectral changes in refractive index of YFs at OP and e-irradiation which ought to be induced as well, according to the Kramers-Kroënig relations. A study of these changes can be the substance of a future work.

\section{Conclusions}

We report a comparative experimental study of the atenuation spectra transformations for a series of $\mathrm{Yb}$ doped alumino-germano silicate fibers with various $\mathrm{Yb}^{3+}$ contents, occurring as the result of irradiation either by a beam of high-energy electrons or at in-band optical pumping at $977 \mathrm{~nm}$ wavelength. Substantial and complex but different in appearance changes are found to arise within the resonant absorption band of $\mathrm{Yb}^{3+}$ ions (reversible bleaching) while monotonous growth of nonresonant background loss to occur in VIS (darkening). Both the trends are shown to originate from the changes in concentrations of either $\mathrm{Yb}^{3+}$ ions (at electron irradiation) or other centers, seemingly $\mathrm{Yb}^{3+}$ clusters, closely related to single $\mathrm{Yb}^{3+}$ ions and spectrally matching them at $977 \mathrm{~nm}$ (at optical pumping). So, in both cases, i.e. at photodarkening, observed in heavily $\mathrm{Yb}^{3+}$ doped fibers at resonant $(977 \mathrm{~nm})$ optical pumping, and at electron irradiation-induced darkening of the fibers, we can capture a notable role of $\mathrm{Yb}^{3+}$ dopants as the agents, creating high-energy radiation, responsible for formation of color centers in the fibers, and at the same time their role as the sensitizers of these processes.

\section{Acknowledgements}

Author thanks Dr. N.S. Kozlova (MISIS, Moscow, Russia) and Dr. A.D. Guzman Chavez (CIO, Leon, Mexico) for help in making e-irradiation and photodarkening measurements, respectively, and Dr. Yu.O. Barmenkov (CIO, Leon, Mexico) and Dr. N.N. Il'ichev (GPI, Moscow, Russia) for useful discussions.

\section{References}

[1] H. M. Pask, R. J. Carman, D. C. Hanna, A. C. Tropper, C. J. Mackechnie, P. R. Barber and J. M. Dawes, "Ytter- 
bium-Doped Silica Fiber Lasers: Versatile Sources for the 1 - $1.2 \mu \mathrm{m}$ Region," IEEE Journal of Quantum Electronics, Vol. 1, No. 1, 1995, pp. 2-13.

doi: $10.1109 / 2944.468377$

[2] D. J. Richardson, J. Nilsson and W. A. Clarkson, "HighPower Fiber Lasers: Current Status and Future Perspectives," Journal of Optical Society of America B, Vol. 27, No. 11, 2010, pp. B63-B92. doi:10.1364/JOSAB.27.000B63

[3] J. J. Koponen, M. J. Soderlund, H. J. Hoffman and S. K. T. Tammela, "Measuring Photodarkening from Single-Mode Ytterbium Doped Silica Fibers," Optics Express, Vol. 14, No. 24, 2006, pp. 11539-11544. doi:10.1364/OE.14.011539

[4] J. Kirchhof, S. Unger, A. Schwuchow, S. Grimm and V. Reichel, "Materials for High-Power Fiber Lasers," Journal of Non-Crystalline Solids, Vol. 352, No. 23-25, 2006, pp. 2399-2403. doi:10.1016/j.jnoncrysol.2006.02.061

[5] I. Manek-Honninger, J. Boullet, T. Cardinal, F. Guillen, M. Podgorski, R. Bello Doua and F. Salin, "Photodarkening and Photobleaching of an Ytterbium-Doped Silica Double-Clad LMA Fiber," Optics Express, Vol. 15, No. 4, 2007, pp. 1606-1611. doi:10.1364/OE.15.001606

[6] S. Jetschke, S. Unger, U. Ropke and J. Kirchhof, "Photodarkening in Yb Doped Fibers: Experimental Evidence of Equilibrium States Depending on the Pump Power," Optics Express, Vol. 15, No. 4, 2007, pp. 14838-14843. doi:10.1364/OE.15.014838

[7] T. Kitabayashi, M. Ikeda, M. Nakai, T. Sakai, K. Himeno and K. Ohashi, "Population Inversion Factor Dependence of Photodarkening of Yb-Doped Fibers and Its Suppression by Highly Aluminum Doping," Optical Fiber Communications Conference, Anaheim, 5 March 2006. doi:10.1109/OFC.2006.215694

[8] A. D. Guzman Chavez, A. V. Kir'yanov, Y. O. Barmenkov and N. N. Il'ichev, "Reversible Photo-Darkening and Resonant Photo-Bleaching of Ytterbium-Doped Silica Fiber at in-Core $977 \mathrm{~nm}$ and $543 \mathrm{~nm}$ Irradiation," Laser Physics Letters, Vol. 4, No. 10, 2007, pp. 734-739. doi:10.1002/lapl.200710053

[9] J. Koponen, M. Soderlund, H. J. Hoffman, D. A. V. Kliner, J. P. Koplow and M. Hotoleanu, "Photodarkening Rate in Yb-Doped Silica Fibers," Applied Optics, Vol. 47, No. 9, 2008, pp. 1247-1256. doi:10.1364/AO.47.001247

[10] J. Koponen, M. Laurila and M. Hotoleanu, "Inversion Behavior in Core- and Cladding-Pumped Yb-Doped Fiber Photodarkening Measurements," Applied Optics, Vol. 47, No. 9, 2008, pp. 4522-4528. doi:10.1364/AO.47.004522

[11] S. Yoo, C. Basu, A. J. Boyland, C. Sones, J. Nilsson, J. K. Sahu and D. Payne, "Photodarkening in Yb-Doped Aluminosilicate Fibers Induced by $488 \mathrm{~nm}$ Irradiation," $O p$ tics Letters, Vol. 32, No. 12, 2007, pp. 1626-1628. doi:10.1364/OL.32.001626

[12] M. Engholm, L. Norin and D. Aberg, "Improved Photodarkening Resistivity in Ytterbium-Doped Fiber Lasers by Cerium Codoping," Optics Letters, Vol. 34, No. 8, 2009, pp. 1285-1287. doi:10.1364/OL.34.001285
[13] M. Engholm, P. Jelger, F. Laurell and L. Norin, "Strong UV Absorption and Visible Luminescence in YtterbiumDoped Aluminosilicate Glass under UV Excitation," $O p$ tics Letters, Vol. 32, No. 22, 2007, pp. 3352-3354. doi:10.1364/OL.32.003352

[14] S. Suzuki, H. A. McKay, X. Peng, L. Fu and L. Dong, "Highly Ytterbium-Doped Silica Fibers with Low PhotoDarkening," Optics Express, Vol. 17, No. 12, 2009, pp. 9924-9932. doi:10.1364/OE.17.009924

[15] B. P. Fox, Z. V. Schneider, K. Simmons-Potter, W. J. Thomes Jr., D. C. Meister, R. P. Bambha, D. A. V. Kliner and M. J. Soderlund, "Gamma Radiation Effects in $\mathrm{Yb}$ Doped Optical Fiber," Fiber Lasers IV: Technology, Systems, and Applications, Proceedings of SPIE, San Jose, Vol. 6453, 22 January 2007, paper 645328, pp. 1-8. doi: $10.1117 / 12.712244$

[16] T. Arai, K. Ichii, S. Tanigawa and M. Fujimaki, "Gamma-Irradiation-Induced Photodarkening in YtterbiumDoped Silica Glasses," Fiber Lasers VIII: Technology, Systems, and Applications, Proceedings of SPIE, San Francisco, 24 January 2011, Vol. 7914, paper 79140K, pp. 1-6.

[17] N. Groothoff, J. Canning, M. Aslund and S. Jackson, "193 nm Photodarkening of Ytterbium-Doped Optical Fibre," OSA Meeting on Bragg Gratings, Photosensitivity, and Poling in Glass Waveguides, Quebec City, 2-6 September 2007, paper BTuC2.

[18] A. V. Kir'yanov, Yu. O. Barmenkov, I. Lucio Martinez, A. S. Kurkov and E. M. Dianov, "Cooperative Luminescence and Absorption in Ytterbium-Doped Silica Fiber and the Fiber Nonlinear Transmission Coefficient at $\lambda=$ $980 \mathrm{~nm}$ with a Regard to the Ytterbium Ion-Pairs' Effect," Optics Express, Vol. 14, No. 9, 2006, pp. 39813992. doi:10.1364/OE.14.006983

[19] C. G. Carlson, K. E. Keister, P. D. Dragic, A. Croteau, and J. G. Eden, "Photoexcitation of Yb-Doped Aluminosilicate Fibers at $250 \mathrm{~nm}$ : Evidence for Excitation Transfer from Oxygen Deficiency Centers to $\mathrm{Yb}^{3+}$," Journal of Optical Society of America B, Vol. 27, No. 10, 2010, pp. 2087-2094. doi:10.1364/JOSAB.27.002087

[20] Z. Burshtein, Y. Kalisky, S. Z. Levy, P. Le Boulanger and S. Rotman, "Impurity Local Phonon Nonradiative Quenching of Yb Fluorescence in Ytterbium-Doped Silicate Glasses," IEEE Journal of Quantum Electronics, Vol. 36, No. 8, 2000, pp. 1000-1007. doi:10.1109/3.853562

[21] G. Stryganyuk, S. Zazubovich, A. Voloshinovskii, M. Pidzyrailo, G. Zimmerer, R. Peters and K. Petermann, "Charge Transfer Luminescence of $\mathrm{Yb}^{3+}$ Ions in LiY1 -xYbxP4O12 Phosphates," Journal of Physics: Condensed Matter, Vol. 19, No. 47, 2007, Article No. 036202. doi:10.1088/0953-8984/19/3/036202

[22] S. Girard, Y. Ouerdane, G. Origlio, C. Marcandella, A. Boukenter, N. Richard, J. Baggio, P. Paillet, M. Cannas, J. Bisutti, J.-P. Meunier and R. Boscaino, "Radiation Effects on Silica-Based Preforms and Optical Fibers I: Experimental Study with Canonical Samples," IEEE Transactions of Nuclear Science, Vol. 35, No. 5, 2008, pp. 3473-3482. doi:10.1109/TNS.2008.2007297 
[23] M. N. Zervas, F. Ghiringhelli, M. K. Durkin and I. Crowe, "Distribution of Photodarkening-Induced Loss in YbDoped Fiber Amplifiers," Fiber Lasers VIII: Technology, Systems, and Applications, Proceedings of SPIE, San Francisco, Vol. 7914, 24 January 2011, paper 79140L, pp. $1-8$.

[24] F. Mady, M. Benabdesselam and W. Blanc, "Thermoluminescence Characterization of Traps Involved in the Photodarkening of Ytterbium-Dopes Silica Fibers," $\mathrm{Op}$ tics Letters, Vol. 35, No. 21, 2011, pp. 3541-3543. doi:10.1364/OL.35.003541

[25] K. E. Mattsson, S. N. Knudsen, B. Cadier and T.Robin, "Photo Darkening in Ytterbium Co-Doped Silica Material," Fiber Lasers V: Technology, Systems, and Applications, Proceedings of SPIE, San Jose, Vol. 6873, 21 January 2008, paper 68731C, pp. 1-11. doi:10.1117/12.763117

[26] S. Sen, R. Rakhmatullin, R. Gubaydullin and A. Silakov, "A Pulsed EPR Study of Clustering of Yb3+ Ions Incorporated in $\mathrm{GeO} 2$ Gass," Journal of Non-Crystalline Solids, Vol. 333, No. 1, 2004, pp. 22-27. doi:10.1016/j.jnoncrysol.2003.09.051

[27] M. Engholm and L. Norin, "Comment on 'Photo Darkening in Yb-Doped Aluminosilicate Fibers Induced by 488 nm Irradiation'," Optics Letters, Vol. 33, No. 11, 2008, pp. 1216-1218. doi:10.1364/OL.33.001216

[28] S. Yoo, C. Basu, A. J. Boyland, C. Sones, J. Nilsson, J. K. Sahu and D. Payne, "Reply to Comment on 'Photodarkening in Yb-Doped Aluminosilicate Fibers Induced by 488 nm Irradiation'," Optics Letters, Vol. 33, No. 11, 2008, pp. 1217-1218. doi:10.1364/OL.33.001217

[29] H. J. Schugar, E. I. Solomon, W. L. Cleveland and L. Goodman, "Simultaneous Pair Electronic Transitions in $\mathrm{Yb}_{2} \mathrm{O}_{3}$," Journal of American chemical Society, Vol. 97, No. 22, 1975, pp. 6442-6450. doi:10.1021/ja00855a024

[30] F. Auzel and P. Goldner, "Towards Rare-Earth Clustering Control in Doped Glasses," Optical Materials, Vol. 16, No. 11, 2001, pp. 93-103. doi:10.1016/S0925-3467(00)00064-1

[31] A. Lupei and V. Lupei, "RE ${ }^{3+}$ Pairs in Garnets and Sesquioxides," Optical Materials, Vol. 24, No. 1-2, 2003, pp. 181-189. doi:10.1016/S0925-3467(03)00123-X

[32] M. A. Noginov, G. B. Loutts, C. S. Steward, B. D. Lucas, D. Fider, V. Peters, E. Mix and G. Huber, "Spectroscopic Study of $\mathrm{Yb}$ Doped Oxide Crystals for Intrinsic Optical Bistability," Journal of Luminiscence, Vol. 96, No. 2-4, 2002, pp. 129-140. doi:10.1016/S0022-2313(01)00210-1

[33] B. Morasse, S. Chatigny, E. Gagnon, C. Hovington, J.-P. Martin and J.-P. de Sandro, "Low Photodarkening Single
Cladding Ytterbium Fibre Amplifier," Fiber Lasers IV: Technology, Systems, and Applications, Proceedings of SPIE, San Jose, Vol. 6453, 26 January 2009, paper 64530H, pp. 1-8. doi:10.1117/12.700529

[34] R. Peretti, A.-M. Jurdyc, B. Jacquier, C. Gonnet, A. Pastouret, E. Burov and O. Cavani, "How do Traces of Thulium can Explain Photodarkening in Yb-Doped Fibers?," Optics Express, Vol. 18, No. 19, 2010, pp. 20455-20460. doi:10.1364/OE.18.020455

[35] S. Jetschke, M. Leich, S. Unger, A. Schwuchow and J. Kirchhof, "Influence of Tm- or Er-Codoping on the Photodarkening Kinetics in Yb Fibers," Optics Express, Vol. 19, No. 15, 2011, pp. 14473-14478. doi:10.1364/OE.19.014473

[36] R. Paschotta, J. Nilsson, P. R. Barber, J. E. Caplen, A. C. Tropper and D. C. Hanna, "Lifetime Quenching in $\mathrm{Yb}$ Doped Fibres," Optics Communications, Vol. 136, No. 56, 1997, pp. 375-378. doi:10.1016/S0030-4018(96)00720-1

[37] A. Iho, M. Soderlund, J. J. Montiel i Ponsoda, J. Koponen and S. Honkanen, "Modeling Inversion in an Ytterbium-Doped Fiber," Optical Components and Materials VI, Proceedings of SPIE, San Jose, 26 January 2009, paper 721209, pp. 1-8.

[38] M. P. Hehlen, N. J. Cockroft, T. R. Gosnell and A. J. Bruce, "Spectroscopic Properties of Er and $\mathrm{Yb}$-Doped Soda-Lime Silicate and Aluminosilicate Glasses," Physical Review, Vol. 56, No. 15, 1997, pp. 9302-9318. doi:10.1103/PhysRevB.56.9302

[39] V. Peters, "Growth and spectroscopy of Ytterbium-doped sesquioxides," PhD dissertation, Hamburg, 2001.

[40] P. Barua, E. H. Sekiya, K. Saito and A. J. Ikushima, "Influences of $\mathrm{Yb}^{3+}$ Concentration on the Spectroscopic Properties of Silica Glass," Journal of Non-Crystalline Solids, Vol. 354, No. 42-44, 2008, pp. 4760-4764. doi:10.1016/j.jnoncrysol.2008.04.020

[41] F. Auzel, "A Fundamental Self-Generated Quenching Center for Lanthanide-Doped High-Purity Solids," Journal of Luminiscence, Vol. 100, No. 1-4, 2002, pp. 125130. doi:10.1016/S0022-2313(02)00457-X

[42] F. Auzel, "Upconversion and Anti-Stokes Processes with $\mathrm{f}$ and d Ions in Solids," Chemicals Review, Vol. 104, No. 1, 2004, pp. 139-173. doi:10.1021/cr020357g

[43] M. Leich, F. Just, A. Langner, M. Such, G. Schotz, T. Eschrich and S. Grimm, "Highly Efficient Yb-Doped Silica Fibers Prepared by Powder Sinter Technology," Optics Letters, Vol. 36, No. 9, 2011, pp. 1557-1559. doi:10.1364/OL.36.001557 